\title{
Justification of application of new types of fastening of slopes of hydraulic engineering constructions
}

\author{
Anatoly Smyvalov ${ }^{1}$, Maxim Rodionov ${ }^{1, *}$, and Yulia Galitskova ${ }^{1}$ \\ ${ }^{1}$ Samara State Technical University, Institute of Architecture and Civil Engineering, \\ 194, Molodogvardeyskaya St., 443001, Samara, Russia.
}

\begin{abstract}
The article represents the analysis of various types of fastenings of the soil slopes which have found broad application in the hydrotechnical construction practice for the last $10-15$ years. It is noted that, generally, new types of fastenings represent composite materials made of concrete, metal and polymers. Experience shows that producers of the construction materials used in bank protection designs seek to recommend them for the solution of a wide range of tasks, at the same time it isn't always founded. The authors, on the basis of the analysis of experience with the types of fastenings and also modern domestic and foreign recommendations about their design and construction, offer a technique of justification of new types of fastenings of slopes of hydraulic engineering constructions. The use of concrete filled geotextile mats in bank protection is brought out as a practical realization of the represented technique.
\end{abstract}

\section{Introduction}

The construction industry dynamically develops that is connected with the new building constructions, technologies and materials. In the hydrotechnical construction it is possible to observe similar tendencies, in particular in the field of protection of soil slopes against the destroying external influence. The reliable protection of soil slopes is extremely important as their destruction can lead to serious accidents in the water-engineering system or at bank protection constructions and as a result on adjacent territories. Therefore the slope fastening design has to be quite reliable for a long period of time.

For the last 10-15 years in Russia and the Samara region, in particular, excepting traditional types of fastenings made of stone, concrete and reinforced concrete, "new" constructive decisions [1-6] are being made to use universal flexible protective concrete mats (UFPCM), concrete filled geotextile mats (CFGM), the polymeric and composite tongue, gabions, etc.

Structurally new types of fastenings are almost all composite materials made of concrete, metal and polymers. So, UFPCM consist of the concrete blocks which are tied around by a metal or polymeric cable, CFGM is a woven polymeric cover filled with concrete; the composite tongue consists of a fabric basis and a special hardener.

*Corresponding author: rodionov_max@mail.ru 
Bank protection fastenings function in very severe conditions: waves, current, ice, vessels, etc. Therefore it is essential for them to withstand all possible influences.

Design features of new types of fixings don't allow to fully use the existing normative and technical basis for their application. The area and conditions of application of new types of fixings are, as a rule, are specified in the technical documentation provided by the vendor. Often vendors tend to recommend the produce to solve a wide range of problems (fixing in a zone higher than a water boundary and variable level, berthing facilities, in a zone of ice and wave actions), which isn't always justified. As a rule, reasoning comes down to the theoretical calculations which aren't confirmed with full-scale data. So, vendors of UFPC represent theoretical researches of their produce functioning in wave and ice conditions. But they do not consider ice piling or berth impact. Also there are no full-scale confirmations of reliability of the received theoretical researches.

\section{Materials and Methods}

To justify the application of new types of fastening of slopes of hydraulic engineering constructions the following methods were used:

- the statistical analysis of the data obtained as a result of the natural survey and observation of coastal slopes, elements of fastening of soil dams, building the fastening of earth constructions of bridge crossings;

- studying of materials properties, with the subsequent calculation of economic efficiency to choose the optimal constructive and technology solution.

The authors have analysed the experience with new types of fastenings of slopes at a number of sites in the Samara region as well. The authors were personally involved in developing and justification of constructive decisions [1].

CFGM INKOMAT have been applied on the site of the Kirovsky bridge crossing. Laying of the first square meters was executed in 2010. Fastening is executed from CFGM on a slope of a road embankment to protect it from washout in the spring high water. The average thickness of fastening is $18 \mathrm{~cm}$ (figure 1).

Similar CFGM (figure 2) were applied on the Mikhaylo Ovsyansky water-engineering system in 2015. The Mikhaylo-Ovsyansky water-engineering system is Class IV and works of laying CFGM were among urgent antiflood actions connected with a considerable destruction of fastening of a pressure head slope of the soil dam and a possible danger of its destruction by the next high water. The works were executed in the winter period and allowed to gather water in a reservoir during the first high water practically to mark NBL without danger of destruction of the soil dam.

UFPCM were applied when performing fastening of the river Pestravochka bank (Pestravka, the Samara region). The design of UFPCM provides reliable «sticking» of a protective cloth from mats to the protected surface. Moreover, the effect of immersion of extreme ranks of the UFPCM concrete blocks in soil is noted. When laying UFPCM on the soil of clay type (sandy loam, loam, clay) it should be made with a rough party of a mat down which allows to increase coupling with soil. The edge of a mat of UFPCM-202 contacts the mattress of Renault laid on the horizontal surface.

The composite and PVC tongue have been applied on bank protection sites in the village of Rozhdestveno and Lunacharsky of the Samara region (figure 4). 


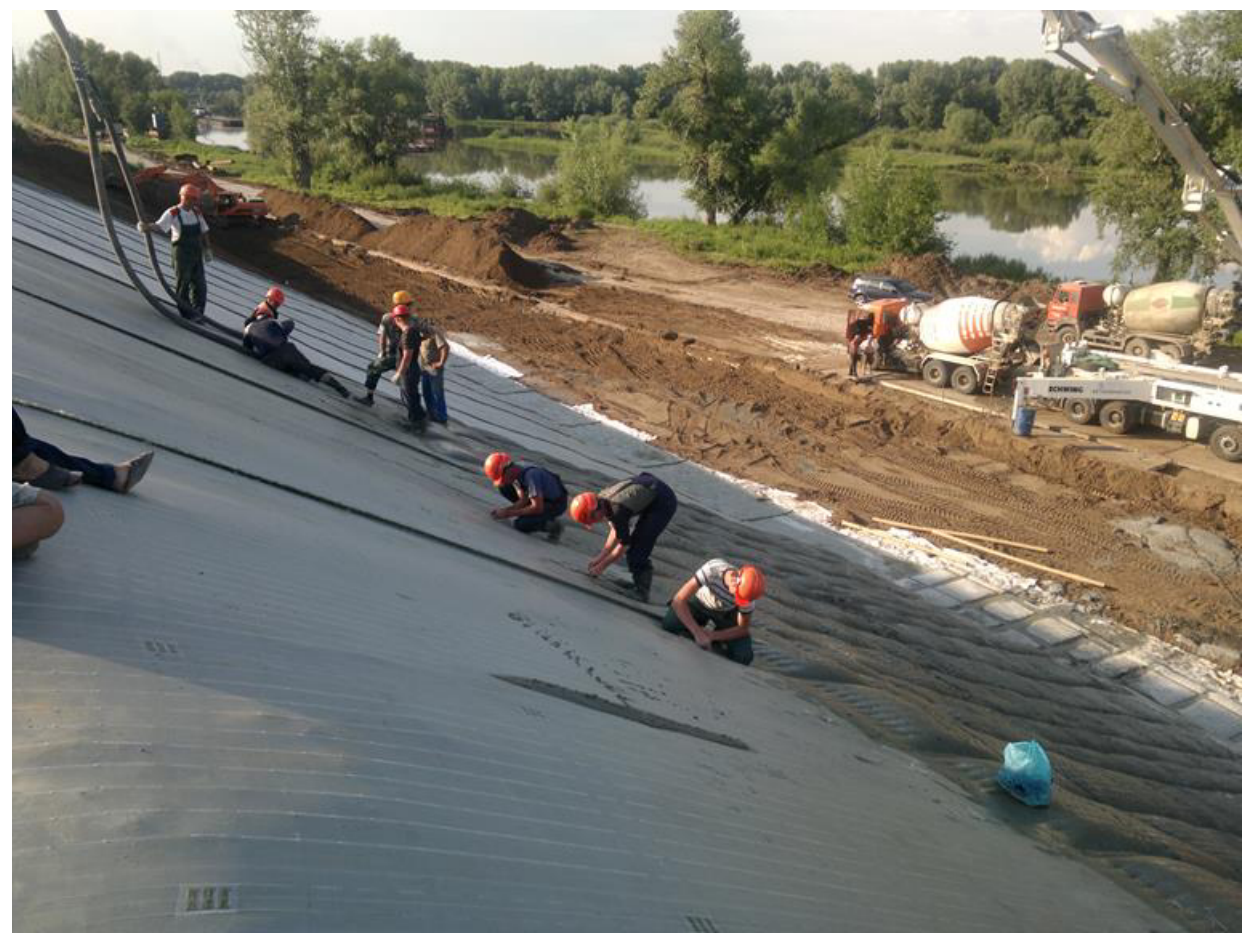

Fig. 1. Construction of "Kirovsky Bridge" (author's photo).

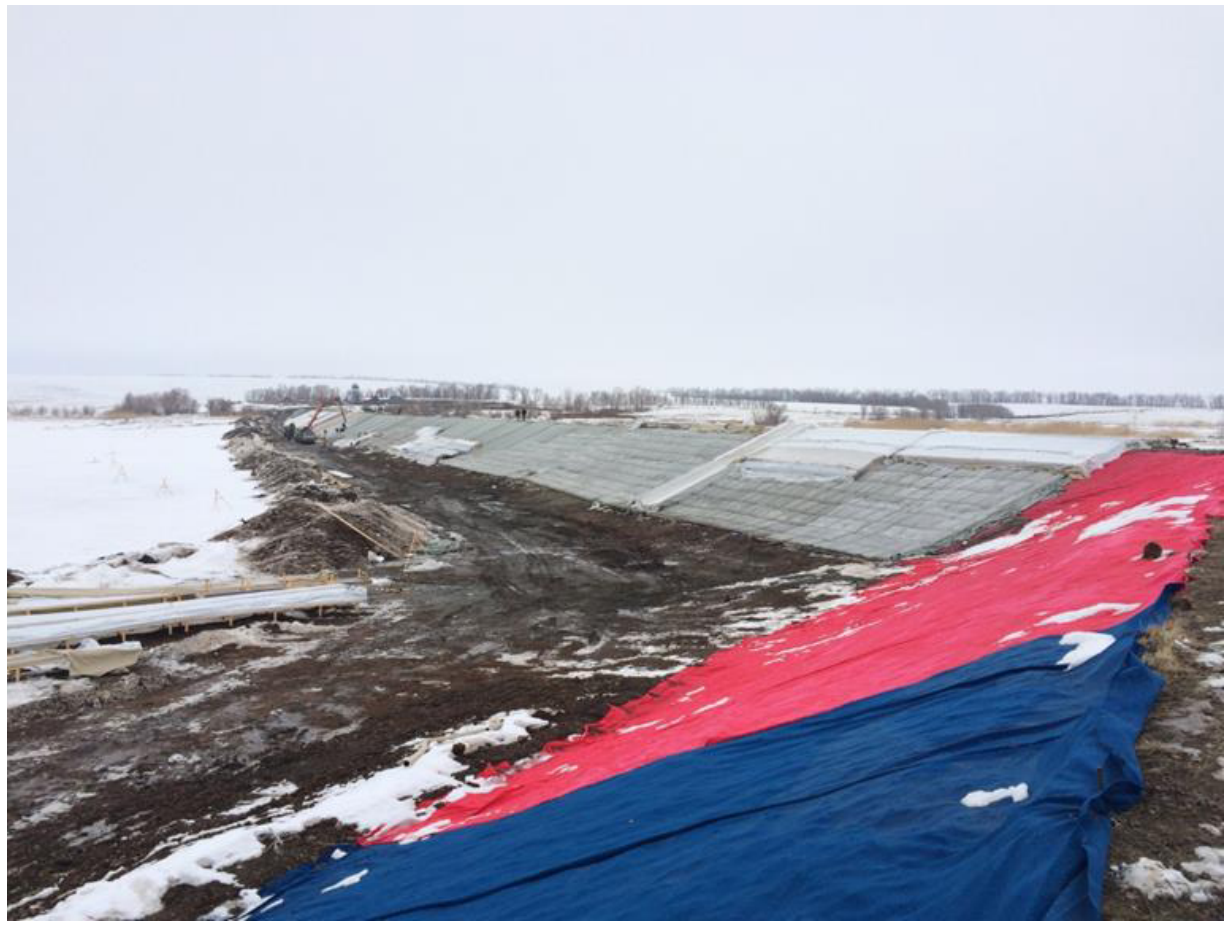

Fig. 2 A reconstruction stage of the water-engineering system in the village of Mikhaylo-Ovsyanka (the author's photo). 


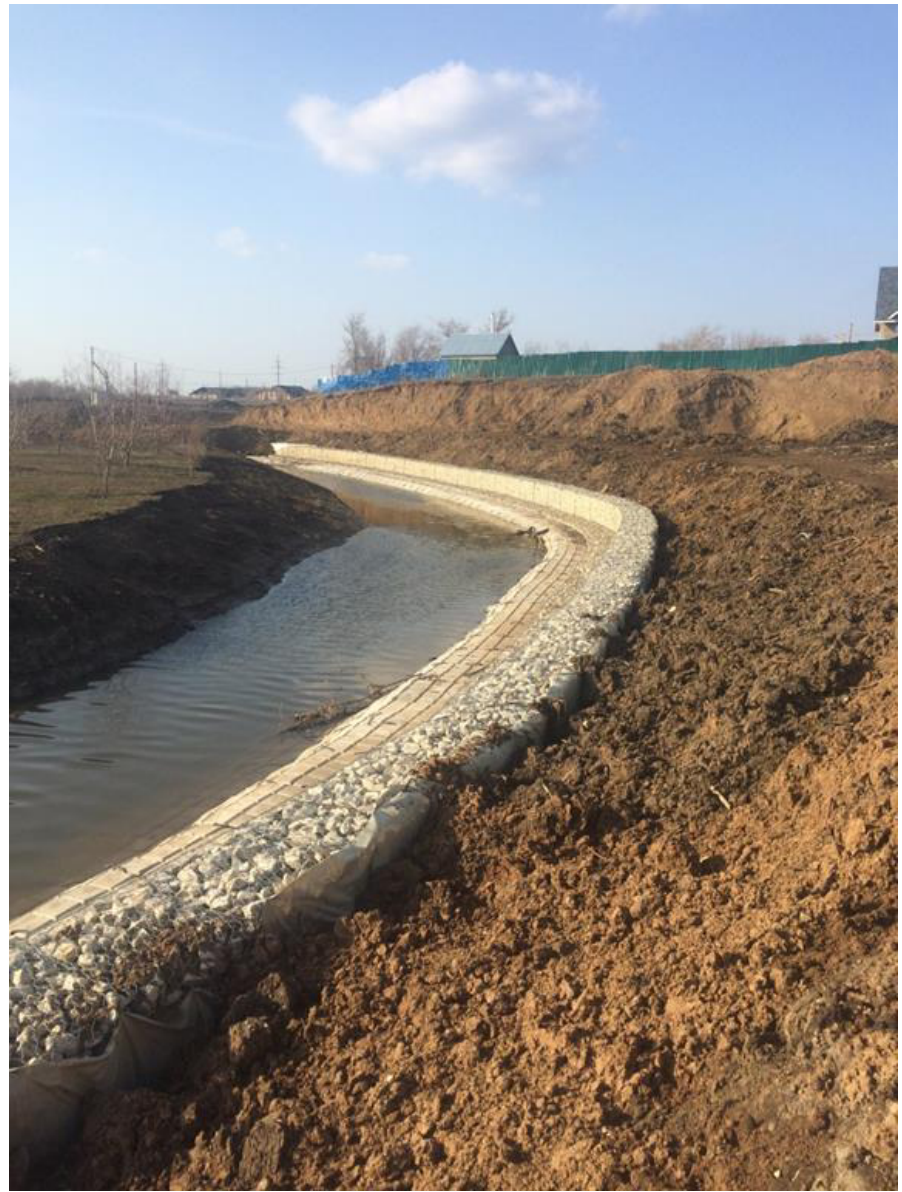

Fig. 3. Fastening of a slope of the river Pestravochka (author's photo).

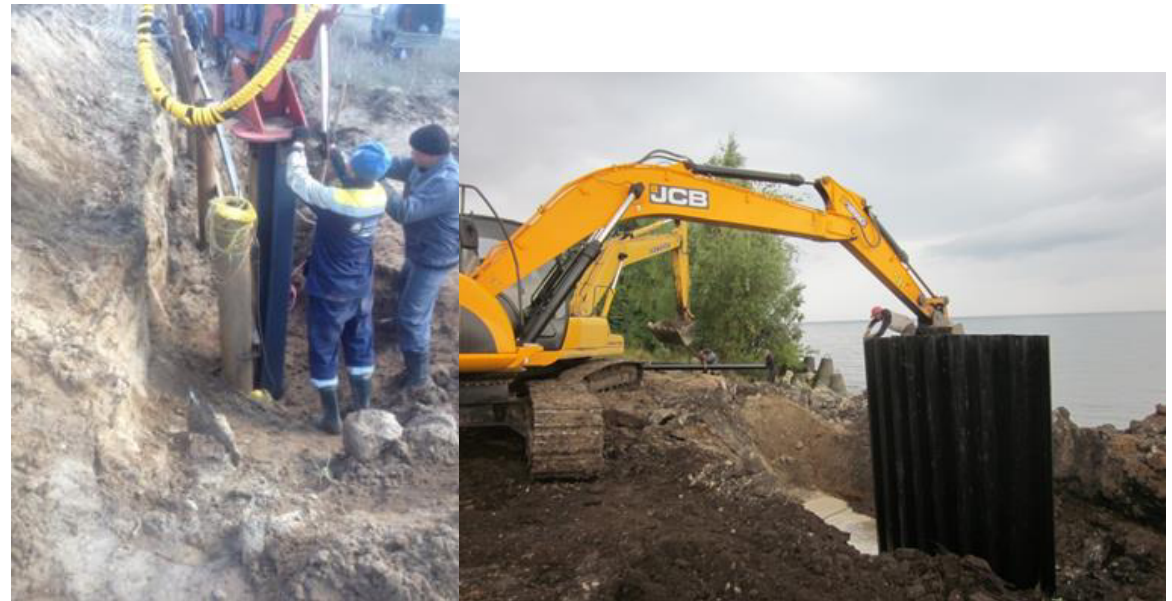

Fig. 4. Building of fastening with the use of tongues: $1-\mathrm{PVC}, 2$ - composite.

At justification of the fastening design standard calculations of durability, stability were used. However, the peculiarities of the considered designs are the following: the producers gave no recommendations how to use these materials in the conditions of ice influences as 
they were used only in "soft" climatic conditions. In this regard, the research of "new" types and sorts of materials in hydrotechnical construction is urgent.

Also on the basis of the technical and economic calculations [7], it is found out that the most economical designs are those of a better type with the use of UFPCM and CFGM. Vertical designs are applied in case of impossibility to use batter designs. The PVC tongue is recommended to be used with a vertical clearance of about two meters and sandy soil of the basis, the composite one - with a vertical clearance of about four meters.

\section{Results}

At designing bank protection constructions we have developed the following research methodology.

During researches the following types of works were carried out:

- theoretical researches and calculations;

- production on the building site;

- laboratory researches of the bearing ability;

- production of the pilot block;

- organization of a hydrometeorological office;

- field researches of ice influences.

The vertical profile wasn't further considered owing to being less economical. On the batter fastening the ice cover has various impacts, the most important of them are the following loadings:

- of the moving ice floe on the batter profile construction;

- of the influence of the stopped even ice floe leaning on the construction under the influence of a water current and wind;

- on constructions from a continuous ice cover at its temperature expansion;

- of the ice cover frozen to the construction at a water level change.

In engineering calculations in the conditions of ice influences it is necessary to consider the following loadings: of the moving ice floe on the batter profile construction; of the influence of the stopped even ice floe leaning on the construction under the influence of a water current and wind; on constructions from a continuous ice cover at its temperature expansion; of the ice cover frozen to the construction at a water level change.

The reliability of a bank protection design in the conditions of ice influences has to be defined with ensuring its being resistant to the shift along a slope and capsizing relative to a top or lower edge.

On the basis of methods of calculation of ice influences and the accounting of design features the conditions of its being resistant to the shift and capsizing are determined by formulas 1 and 2 . The providing condition of concrete mats being resistant to the shift within the ice foe is defined as follows:

$$
K=\frac{\sum T_{1}}{\sum T_{2}} \geq \gamma_{n},
$$

where $\mathrm{K}$ - stability coefficient; $\Sigma \mathrm{T}_{1}$ - the sum of all holding forces, $\mathrm{kN} ; \Sigma \mathrm{T}_{2}$ - the sum of all shifting forces, $\mathrm{kN} ; \gamma_{\mathrm{n}}-$ reliability coefficient accepted depending on a class of hydraulic engineering constructions.

$$
K=\frac{\sum M_{1}}{\sum M_{2}} \geq \gamma_{n},
$$


where $\Sigma \mathrm{M}_{1}$ - the sum of the moments of all holding forces; $\Sigma \mathrm{M}_{2}-$ the sum of the moments of all shifting forces.

For the majority of "new" materials similar researches weren't conducted therefore, they were used in the zone of a variable level at the considered objects construction sites. For justification of using CFGM we have conducted special researches, including the pilot block setting-up where observations are currently carried out. Similar researches were conducted for UFPCM [8] which have shown that they are allowed to be used on flat laying (more than 4), the minimum thickness of ice (approximately about $0,7 \mathrm{~m}$ ) and/or in an underwater part of the construction. In this regard all further results of researches are devoted to studying of CFGM.

On the basis of field observations the basic data have been established for calculation. The ice influences observed: the maximum thickness of ice is $0,60 \mathrm{~m}$; the maximum fluctuations of water level in a reservoir at a freeze-up are one meter; the maximum fluctuations of temperature of external air within a day are seven degrees Celsius, the maximum speed of the water current under ice in the ice drift period is $V=3,0 \mathrm{~m} / \mathrm{s}$, the maximum wind speed in the period of the ice drift is $\mathrm{V}=10,0 \mathrm{~m} / \mathrm{s}$, the average length of the ice foe in the downstream is $\mathrm{L}=30.0 \mathrm{~m}$, a bias of a stream surface, $\mathrm{i}=0,07$. On the basis of the actual data obtained as a result of the observation, the calculations for three types of mats are carried out and represented in Table 1.

The results of the observations made by us at the pilot block are represented in the following scientific works [9-10]. As a result of the conducted researches at the pilot block the possibility of using CFGM in the zone of the ice drift and influence of ice foes on the rivers and reservoirs has been proved.

Table 1. Calculation results of mats stability.

\begin{tabular}{|c|c|c|c|c|c|c|c|c|c|c|c|c|c|c|c|}
\hline \multirow{2}{*}{ 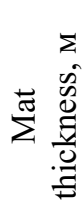 } & \multicolumn{3}{|c|}{ Of ice drift } & \multicolumn{3}{|c|}{$\begin{array}{c}\text { Of } \\
\text { leaning }\end{array}$} & \multicolumn{3}{|c|}{$\begin{array}{c}\text { Of } \\
\text { temperature } \\
\text { expansion }\end{array}$} & \multicolumn{3}{|c|}{$\begin{array}{l}\text { Of level } \\
\text { change }\end{array}$} & \multicolumn{3}{|c|}{ Capsizing } \\
\hline & $\vec{W}$ & $\stackrel{\sim}{\omega}$ & $x$ & $\overrightarrow{\mathrm{W}}$ & 氙 & $x$ & 氙 & $\stackrel{\sim}{\omega}$ & 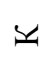 & 忎 & $\stackrel{\sim}{\omega}$ & 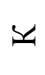 & $\sum_{\text {出 }}$ & $\sum_{\omega}^{N}$ & $\leq$ \\
\hline 0,1 & $\frac{n}{\sigma}$ & N & ? & $\hat{n}$ & तै & $\stackrel{\sigma_{0}}{\sim}$ & to & $\stackrel{m}{n}$ & 工ુ & $\begin{array}{l}m \\
\infty \\
+\end{array}$ & กิ & $\stackrel{+}{\sim}$ & $\stackrel{2}{2}$ & $\underset{\infty}{+\infty}$ & â \\
\hline 0,2 & $\stackrel{+}{\stackrel{+}{n}}$ & $\stackrel{+}{\sim}$ & $\tilde{n}$ & $\stackrel{N}{f}$ & 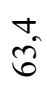 & $\stackrel{\sigma_{n}}{-}$ & $\begin{array}{l}\vec{\sigma} \\
\stackrel{\sigma}{\sigma}\end{array}$ & $\hat{\rho}$ & 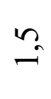 & $\begin{array}{l}\overrightarrow{0} \\
i n\end{array}$ & 2 & $\stackrel{\sigma}{\sigma}$ & $\stackrel{2}{2}$ & $\begin{array}{l}0 \\
\infty \\
\sim \\
\sim\end{array}$ & $\hat{m}$ \\
\hline 0,3 & $\frac{0}{6}$ & $\begin{array}{l}0 \\
\dot{m}\end{array}$ & ㄱ & $\stackrel{\nabla_{n}}{n}$ & $\stackrel{r}{\curvearrowright}$ & $\stackrel{\sigma_{a}}{-}$ & $\begin{array}{l}\dot{\sigma} \\
\stackrel{\sigma}{+}\end{array}$ & 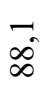 & $\underline{a}$ & $\begin{array}{l}\text { ñ } \\
\text { ה }\end{array}$ & $\hat{\infty}$ & $\stackrel{\sigma}{\sigma}$ & $\stackrel{2}{2}$ & $\stackrel{0}{\text { ते }}$ & $\stackrel{\gamma}{\nabla}$ \\
\hline
\end{tabular}

\section{Discussion}

Theoretical researches have shown that owing to numerous factors of the ice influences and conditions of interaction of the sheeting and it isn't possible to develop universal recommendations to use a certain new material type and design. When calculating it is necessary to take into account all ice influences, four types possible, on the basis of these long-term observations of ice foes formation around the alleged construction site. Theoretical researches have shown that the most adverse are influences from the thermal ice expansion and the frozen ice cover at a water level change. 
Theoretical researches of mats standard types have shown that the most adverse are influences from the thermal expansion of ice and the frozen ice cover at a water level change. In this regard for mats to be reliable, an important factor of stability is ensuring collaboration of separate "pillows" of a mat. The collaboration is ensured by preserving woven covers of a mat, first of all the lower part and connecting elements between the top and lower fabric for the entire period of operation of the construction, and also by connecting contacting rolls according to the laying instruction. Stability calculations have to be carried out as for all massif of the mat laid on a slope.

CFGM can be used in ice conditions at observance of certain requirements.

\section{Conclusions}

The conducted researches have shown:

1. Modern «new» materials allow considerably to lower costs of bank protection constructions.

2. The most economical are designs of a batter type with use of UFPCM and CFGM. Vertical designs are applied in case of impossibility to use the batter ones.

The PVC tongue is recommended to be used with a vertical clearance of about two meters and sandy soil of the basis, the composite one - with a vertical clearance of about four meters.

3. For the majority of «new» materials researches of ice foes influence weren't conducted therefore, at the considered objects construction sites they are recommended to be used in the zone of a variable level higher than the ice level and ice drift.

4. For UFPCM and CFGM special researches are conducted, for BNTM we have created the pilot block where observations are currently carried out. The research has shown a possibility to use widely UFPCM in the conditions of ice foes influence. The conducted researches have shown a possibility to use them in conditions shift stability, capsizing stability and durability.

\section{References}

1. M.I. Balzannikov, A.A. Mikhasek, Procedia Engineering 91, 183-187 (2014)

2. M.G. Litvinova, Scientific Survey 13, 70-74 (2016)

3. Andrey Mikhasek, Boris Ivanov MATEC Web of Conferences 105, 03022 (2017)

4. A.A. Mikhasek, A.A. Smyvalov, Scientific Survey 14, 102-109. (2015)

5. Y.E. Senitskij, A.A. Mikhasek, A.V. Kozlov, Scientific Survey 23, 64-70 (2015)

6. A.A. Mikhasek Scientific Survey 14, 67-72 (2016)

7. A.A. Mikhasek, M.V. Rodionov, Procedia Engineering 111, 82-88 (2015)

8. Scientific Report for Contract № 72/12-N (Voronezh State University of Architecture and Civil Engineering, Voronezh, 2012)

9. A.A. Mikhasek, M.V. Rodionov, M.G. Litvinova, Scientific Survey 4, 125-134 (2015)

10. Andrey Mikhasek, Maxim Rodionov, Vladimir Seliverstov, and Yury Senitsky, MATEC Web of Conferences 86 DOI: 10.1051/ matecconf/2016 868603002 (2016). 